\title{
De Ricardo a Keynes: Notas sobre a Origem da Macroeconomia.
}

\section{Alexandre Flavio da Silva Andrada}

\begin{abstract}
Resumo: Este artigo reconstrói a narrativa sobre o surgimento da Macroeconomia. Desde o debate sobre o "general glut" (1811-1836), nas primeiras décadas do século XIX, passando pelos debates em torno das chamadas "comercial crisis" (1836-1913), depois pelas teorias de “business cycles' (1913-1936), até a publicação da Teoria Geral em 1936. Além disso, discutem-se algumas hipóteses sobre as causas do sucesso da obra de Keynes.
\end{abstract}

Palavras-Chave: Macroeconomia, Teorias de ciclos econômicos, Teoria Geral, Síntese Neoclássica e Keynes.

Classificação JEL: B10, B22.

\section{From Ricardo to Keynes: Notes on the Origins of Macroeconomics}

\begin{abstract}
This article constructs a narrative about the emergence of Macroeconomics. We present and analyze the debate about the "general glut" (1811-1836) in the early decades of the nineteenth century; the discussions around the so-called "commercial crisis" (1836-1913); the theories diversity of "business cycle" theories from the interwar period, before the publication of the Keynes' General Theory in 1936. In addition, we discuss some hypotheses about the causes of the success of the work of Keynes.
\end{abstract}

Keywords: Macroeconomics, Business Cycles Theories, General Theory, Neoclassical Synthesis and Keynes.

1 Professor do Departamento de Economia da Universidade de Brasília. E-mail: alexandreandrada@ gmail.com. 


\section{Introdução}

Neste artigo, retomamos a questão sobre a origem da Macroeconomia. O estímulo inicial partiu das diferentes leituras que dois influentes economistas - Robert Lucas e Olivier Blanchard - apresentam sobre esse evento. Ainda que eles não sejam especialistas em história das ideias, suas opiniões têm, indubitavelmente, um grande impacto sobre a comunidade dos economistas².

Robert E. Lucas Jr., figura central no ataque ao keynesianismo, durante os anos 1970, e vencedor do prêmio Nobel de 1995, em vários artigos de viés polemistas apresenta o que chamamos de tese da ancestralidade da abordagem equilibrista Novo-Clássica. Seu argumento é que a Macroeconomia fundada por Keynes, entendida como um campo específico e particular da teoria econômica, caracterizouse como um desvio na história das análises de flutuação. Na sua análise, os economistas anteriores a Keynes "não reconheciam a necessidade de um ramo especial da economia, com seus próprios postulados especiais, elaborado para explicar os ciclos econômicos". Keynes teria "fundado essa disciplina chamada macroeconomia por acreditar ser impossível explicar as características dos ciclos econômicos a partir da disciplina imposta pela teoria clássica”. Essa disciplina se sustentava na aceitação de dois postulados: "(a) that markets are assumed to clear and (b) that agents be assumed to act in their own self-interest" (LUCAS \& SARGENT: 1979, p. 58).

Enquanto os "clássicos" definiam funções comportamentais, a partir da teoria da escolha (entendida como aquela teoria comportamental na qual os agentes se comportam de acordo com a hipótese de racionalidade de maximização de utilidade), "Keynes described a model in which rules of thumbs [...] took the place of decisions functions that a classical economist would insist be derived from the theory of choice". Vê-se que Lucas trata os autores anteriores a Keynes como um bloco homogêneo denominado "clássicos". E que esses "clássicos" construíam suas análises baseadas em princípios microeconômicos bastante claros.

Mas como, então, uma abordagem metodologicamente inferior como a keynesiana saiu-se vitoriosa? Primeiramente, Lucas argumenta que a crise de 1929 teria sido um daqueles eventos capazes de alterar os rumos da teoria econômica ${ }^{3}$. A severidade e a longa duração da subutilização dos fatores produtivos teriam tornado os economistas céticos em relação à capacidade explicativa dessas teorias tradicionais, abrindo espaço, assim, para o sucesso de Keynes. Para Lucas, além dessa especifi-

2 Segundo a Revista HOPE - a mais prestigiosa publicação em História do Pensamento Econômico - seu artigo mais citado é um de Esther-Mirjam Sent publicado em 2004. De acordo com o Google Scholar este artigo contava com 151 citações em outubro de 2014. Já o artigo de Blanchard que utilizaremos, foi publicado em 2000 e possuía 249 citações. Enquanto o trabalho "After Keynesian Macroeconomics" de Lucas \& Sargent possui 795 citações.

3 Lucas (1980a) apresenta um esboço de teoria epistemológica, enfatizando duas fontes de evolução no pensamento econômico: (i) eventos econômicos que alteram as perguntas as quais os economistas buscam responder, e; (ii) ampliação de nossa capacidade computacional. 
cidade do momento histórico, que forjara uma plateia particularmente receptiva, o sucesso deveu-se a uma série de eventos alheios às vontades de Keynes. Eventos esses que permitiram a transformação de seu aparato verbal em uma economia artificial com maior grau de falseabilidade que os esquemas alternativos. É o que LUCAS (1980a, p. 701) chama de um "feliz acidente histórico". Esses eventos foram, basicamente, os seguintes: (i) A transformação do aparato verbal da Teoria Geral (TG daqui em diante) em um sistema de gráficos e equações simultâneas, realizada por autores como John Hicks e Franco Modigliani e (ii) $\mathrm{O}$ desenvolvimento da Econometria (e sua aplicabilidade àquela economia) graças, principalmente, aos trabalhos de Jan Tinbergen e Ragnar Frisch. Ambos os eventos são apresentados como opostos à metodologia de Keynes, o qual é caracterizado como uma espécie de obscurantista. Avesso às ferramentas fundamentais para o progresso da disciplina, rejeitara qualquer forma de economia matemática (aqui se utiliza a famosa passagem da Teoria Geral sobre o "labirinto de símbolos pretensiosos”), como também do uso de métodos econométricos (a referência aqui é a crítica de Keynes em sua polêmica com Tinbergen, quando comparou a econometria à alquimia $\left.{ }^{4}\right)$. Outra dimensão da vitória keynesiana seria de cunho sociológico. Lucas (1977; 1980b) discute o surgimento do economista como um técnico capaz de controlar os ciclos econômicos, cuidando para que houvesse sempre pleno emprego. Função essa cuja razão de ser era justificada pela teoria de Keynes.

Já Olivier Blanchard (2000), figura proeminente do Keynesianismo neoclássico dos anos 1980 e autor simpático a Keynes, tem outra interpretação. Sobre a "Macroeconomia" anterior a Teoria Geral (TG daqui em diante), Blanchard (2000) afirma que esse foi um período no qual "a confusão reinava" e isso devido à ausência de um aparato comum. Ou seja, viva-se uma espécie de período pré-paradigmático da disciplina. Em sua visão, "a teoria dos ciclos econômicos não era uma teoria, mas antes uma coleção de explicações, cada uma com sua própria e rica dinâmica”. Essas explicações focavam em um fator específico, que podia ser real (como questões climáticas, mudanças tecnológicas, inovações), expectacional (ondas de otimismo e pessimismo) ou monetárias (comportamento dos bancos e do banco central). E "mesmo quando em moldes de equilíbrio geral, os argumentos, quando lidos hoje, parecem incompletos e de natureza de equilíbrio parcial”. (BLANCHARD, 2000, p. 1376-7).

Sobre as causas do sucesso da TG, Blanchard apresenta um argumento do tipo superação positiva. Como no esquema kuhniano de revolução científica, em meio ao caos surge uma obra capaz de aglutinar em torno de si a maior parte dos pesquisadores da área, fornecendo uma linguagem e um método hegemônico. Mas enquanto em Thomas Kuhn há todo um conjunto de explicações para o domínio de um paradigma, Blanchard afirma que a TG era simplesmente superior aos seus

\footnotetext{
Sobre a Econometria, Lucas trata Keynes tanto como um inimigo da disciplina, como também responsável teórico pelas restrições ad hoc utilizadas na superação do problema de identificação da Econometria tipo Cowles Commission.
} 
rivais. "Uma citação de Pigou... resume bem: Ninguém antes dele... trouxe todos os fatores relevantes, reais e monetários, juntos em um único esquema forma, através do qual suas interações poderiam ser coerentemente investigadas". (BLANCHARD, 2000, p. 1378-9).

As divergências entre as interpretações históricas de Lucas e Blanchard nos levam a explorar essas questões: como era a Macroeconomia anterior a Keynes e quais fatores explicam o sucesso da TG? Essas certamente não são questões inexploradas, tendo sido objeto de escrutínio de vários historiadores do pensamento. A história da Macroeconomia é objeto de excelentes trabalhos como de Dimand (2003). A revolução keynesiana, um dos mais extraordinários eventos na história da Economia, teve suas causas, precedentes, desdobramentos e implicações amplamente analisadas por autores como Klein (1950), Patinkin (1983), Dimand (1988) e Laidler (1999). Nossa contribuição para essa rica literatura baseia-se não apenas em uma interpretação subjetiva sobre esses eventos, mas antes na estruturação de uma narrativa a partir de uma série de dados linguísticos e bibliométricos obtidos junto a dois grandes repositórios de trabalhos acadêmicos: Google (Books e Scholar) e Jstor. Não conhecemos nenhum trabalho que tenha se utilizado dessas ferramentas da forma que as usamos aqui, de maneira que nossa contribuição é original. Além disso, como forma de apresentar o debate em torno das flutuações, tal qual como compreendido por seus participantes, nossa taxonomia das escolas é obtida a partir de resenhas sobre o tema escritas à época de interesse. Dessas resenhas, se destacam as de Kershaw (1900), Persons (1926), Mitchell (1927) e Haberler (1937).

$\mathrm{O}$ artigo está dividido em duas seções além dessa introdução. Na primeira apresentamos uma reconstrução do surgimento da Macroeconomia. $\mathrm{Na}$ segunda parte discorremos sobre as causas do sucesso da TG. Ao final apresentam-se algumas conclusões.

\section{Sobre a Genealogia da Macroeconomia.}

John Stuart Mill (1806-1873), em seu tratado metodológico de 1836, compara a definição de uma disciplina aos muros de uma cidade medieval que surgem não para servir de receptáculo às construções vindouras, mas sim para circunscrever aqueles já existentes. Ou seja, o campo de estudo é sempre anterior à sua definição, de seu descolamento de uma disciplina ancestral. Por isso, a busca por uma origem exata ou por um pioneiro definitivo é sempre tarefa inútil. A depender de como entendemos o que é Macroeconomia, sua origem, em termos de espaço e tempo, pode mudar drasticamente. Usualmente, define-se a Macroeconomia como o resultado da união entre a teoria monetária de David Hume (1711-1776), David Ricardo (1772-1823) e Knut Wicksell (1851-1926) com a de ciclos econômicos de Clément Juglar (1819-1905) e Wesley Mitchell (1874-1948), cujo marco zero seria a publicação d'A Teoria Geral de Keynes em 1936 [v. Dimand (2008). Ainda que aceitemos essas convenções, esse processo se desenvolveu em uma dinâmica complexa. 


\section{1 Sobre o "General Glut" (1811-1836)}

Pensando na fase madura da Economia Política - isso é, após publicação da Riqueza das Nações em 1776 - é certo que a preocupação central dos primeiros economistas políticos era com a dinâmica de longo prazo da economia. Essa preocupação transparece, por exemplo, na própria definição de Economia Política apresentada por Ricardo em seus Princípios. Isso não significa, porém, que aqueles autores estavam totalmente alheios às questões relativas às flutuações. Sowell (2006) define a Macroeconomia do período clássico como fundamentada em duas teorias; a Lei de Say e a Teoria Quantitativa da Moeda.

Sobre o debate em torno das flutuações econômicas podemos, pois, voltar à polêmica ocorrida nas primeiras décadas do século XIX, tendo de um lado David Ricardo (1772-1823) e Jean-Baptiste Say (1767-1832), de outro, Thomas Malthus (17661834) e Jean-Charles-Léonard Simonde de Sismondi (1773-1842), sobre a possibilidade de ocorrência do chamado "general glut". Essa polêmica envolve a rejeição total ou parcial dos princípios [v. Baumol (1977) e Sowell (2006)] associados à Lei de Say (ou lei dos mercados). Acreditamos que é desse debate que partem as raízes da Macroeconomia ${ }^{5}$. Aí se apresentam de maneira embrionária as duas formas e dois métodos de compreensão da dinâmica da economia capitalista: para uns, as crises são setoriais e endogenamente reversíveis em um curto intervalo de tempo, para outros as crises são generalizadas e as forças endógenas de ajuste da economia são débeis ou inexistentes. Para uns, o livre funcionamento do capitalismo gera um inquestionável ótimo social, para outros, ele tende a gerar concentração de renda e desemprego. Uns são adeptos do método abstrato/dedutivo e louvam sempre a análise axiomática, que produz um conhecimento a-histórico e atemporal dos fenômenos econômicos, enquanto outros preferem o método indutivo, preocupando-se com a realidade concreta observada. Chamaremos a primeira de agenda "ricardiana" e a segunda de "sismondiana".

Para os ricardianos a demanda agregada não se configura como um empecilho ao processo de acumulação. Do ponto de vista contábil, todo incremento da produção tem valor necessariamente igual à remuneração dos fatores envolvidos. É essa identidade que é traduzida muitas vezes como "a oferta cria sua própria demanda", forma vulgar de definir a Lei de Say ${ }^{6}$. Desse princípio, sabemos que qualquer incremento na produção de mercadorias gera uma renda exatamente suficiente para adquiri-las. E os homens sempre desejam consumir mais, sendo limitados nesse desejo apenas por sua renda $a^{7}$ Isso significa que qualquer produção será vendida? A resposta dos ricardianos é negativa, pois é possível que em um erro de projeção,

5 Commons, McCraken \& Zeuch (1922), por exemplo, adotam esse procedimento, enquanto Sowell (1963) o rejeita veementemente, criticando inclusive a interpretação de Keynes sobre a teoria de Malthus.

6 Keynes (1936) talvez seja o principal propagador dessa máxima.

7 Ricardo, como Smith, exclui os alimentos desse raciocínio, pois haveria um limite físico do estômago que não poderia ser ultrapassado independentemente da renda adicional adquirida. 
os capitalistas tenham alocado mais capital e trabalho em um dado setor do que o necessário para atender sua demanda ${ }^{8}$. Mas como os capitalistas buscam a melhor maneira de obter o máximo retorno de seus investimentos, é razoável imaginar que esse seria um resíduo de média zero no processo total de produção de mercadorias.

Imaginemos uma economia com dois setores - (1) e (2) - nos quais estão alocados todo o capital $(\mathrm{K})$ e trabalho $(\mathrm{L})$ disponíveis na sociedade. Suponha que, no instante zero, ambos os mercados estão equilibrados, têm uma mesma taxa de lucro e que cada setor emprega $50 \%$ de cada um dos fatores produtivos. Agora, imagine que os empresários acreditam que o setor (1) se tornará mais lucrativo. Isso implicará no deslocamento de capital e trabalho do setor (2) para o setor (1), de tal forma que, por exemplo, o setor (1) fica com $3 / 4$ dos fatores produtivos e o setor (2) com o $1 / 4$ restante. Se não houver mudança na demanda da sociedade, logo ficará claro que há superprodução no setor (1) e subprodução no setor (2). Isso fará com que surja um diferencial de lucro entre os setores, com o setor (2) se tornando mais atrativo. A solução para esse problema de má alocação dos recursos não demanda qualquer intervenção externa, os empresários em busca de lucro irão espontaneamente transferir recursos do setor (1) para o setor (2). Nesse processo de deslocamento dos fatores produtivos, parte do capital e dos trabalhadores ficará fora de atividade - ou seja, há uma queda na produção agregada e no emprego - mas essa situação é temporária e rapidamente reversível.

Para os ricardianos, o excesso de poupança também não seria um problema. Como os agentes buscam o máximo retorno para seus ativos, em tempos de normalidade, qualquer aumento da poupança deveria se dirigir para os bancos, reduzindo assim a taxa de juros e tornando novos projetos de investimentos viáveis. Ou seja, o aumento da poupança não provocaria uma redução na demanda efetiva, mas apenas uma mudança na sua composição; a queda no consumo seria compensada pelo aumento dos investimentos. $\mathrm{O}$ entesouramento - fenômeno que poderia quebrar o funcionamento suave da economia - seria uma anormalidade. E ainda que se observasse uma vulgarização desse expediente no caso de uma crise bancária, por exemplo, o que aconteceria é que à medida que o dinheiro se tornasse escasso, maior seria a taxa de juros de mercado, o que aumentaria o custo de oportunidade de reter dinheiro, exercendo, assim, naturalmente, uma força de arrasto desses recursos em direção ao sistema bancário.

Para os "sismondianos", a expansão da oferta pode não ser acompanhada de igual expansão na demanda agregada. Ou ainda, não há garantias que a demanda efetiva da comunidade será sempre igual à oferta agregada. Para Sismondi (1818), a superprodução seria decorrência do progresso técnico poupador de mão de obra. No caso desse tipo de inovação, permanecendo inalterada a demanda pelo produto, haverá uma redução no montante de trabalhadores empregados no setor. Se para atender a demanda anual de um bem $(x)$ qualquer eram necessárias 10 fábricas que empregavam 100 homens cada um, logo, são 1.000 os trabalhadores envolvidos nesse setor. Imagine que uma daquelas 10 fábricas desenvolve uma tecnologia com a qual utilizando

8 Ver Ricardo in Malthus (1983, p. 186). 
apenas 100 homens ela é capaz de atender toda a demanda (fixa) a um preço menor que o anteriormente praticado. $\mathrm{O}$ que ocorrerá é que as demais fábricas serão fechadas e seus trabalhadores ficarão desempregados'. No argumento de Sismondi (1818, p. 205), tanto o capital físico quanto o trabalhador estão como que presos ao seu setor original. Mesmo que se aumente a remuneração daqueles que permanecem empregados - o que não é uma decorrência necessária do aumento da produtividade, já que há agora mais braços disponíveis no setor - a massa de salários deve ser reduzida em comparação ao equilíbrio anterior. E como os trabalhadores precisam reproduzir sua subsistência continuamente, o desemprego significaria a condenação daquela classe.

Note-se que a teoria dos ciclos apresentada por Karl Marx, tanto no Manifesto Comunista de 1848 quanto n'O Capital de 1863, são muito próximas às de Sismondi ${ }^{10}$. Muito se destaca a influência de Ricardo sobre Marx, mas a influência de Sismondi é igualmente significativa. Marx é, nesse aspecto, um sismondiano. Também Keynes, ao dirigir suas críticas aos ricardianos, partindo da negação da lei de Say e enfatizando a centralidade da demanda efetiva, está dando continuidade a essa agenda de pesquisa. Certo que sua teoria sobre a deficiência da demanda efetiva não repousa em considerações sobre o progresso técnico, mas, como afirmamos anteriormente, são claros os ecos daquela tradição.

\subsection{Sobre as Crises Comerciais (1836-1913)}

A polêmica sobre o "general glut", no entanto, teve vida curta - entre $1811 \mathrm{e}$ 1836 - e encerrou-se com a vitória inequívoca dos ricardianos ${ }^{11}$. O foco da polêmica passará então a ser em torno das causas das crises econômicas ("commercial crisis") que afetavam frequentemente os principais países capitalistas.

A Tabela 1 traz informações sobre a ocorrência dos termos, tanto no Jstor quanto no Google Scholar. Segundo o Jstor, a primeira referência ao termo "general glut" aparece em 1811 em um texto de David Ricardo. Já o Google Scholar se refere a um texto de Jean-Baptiste Say publicado em 1821, sendo ele parte de sua correspondência com Thomas Malthus. O Jstor sugere que o debate sobre as "commercial crisis" teria surgido apenas em 1826, corroborando a ideia de que ele seria posterior à polêmica sobre a lei dos mercados. O Google Scholar, no entanto, aponta para o famoso texto de Proudhon publicado em 1809, anterior a todas as outras publicações. No entanto, a

9 Importante lembrar que no famoso capítulo sobre "A Maquinaria", Ricardo acata parte desses argumentos referentes aos possíveis impactos negativos sobre a classe trabalhadora - e não para o conjunto da economia - das inovações poupadoras de mão de obra.

10 Em uma de suas geniais notas de rodapé, diz Marx: "In this work [Principles of Political Economy], Malthus finally discovers, with the help of Sismondi, the beautiful Trinity of capitalistic production: over-production, over-population, and over-consumption - three very delicate monsters, indeed".

11 Na famosa metáfora de Keynes (1936), Ricardo conquistou a Inglaterra tal qual a Santa Inquisição conquistara a Espanha. 
segunda menção ao termo só aparece em um texto de 1826 - mesma data apontada pelo Jstor - do economista e estatístico inglês Thomas Tooke (1774-1858).

Tabela 1: Informações sobre as ocorrências dos termos "general glut" e "commercial crisis"

\begin{tabular}{c|c|c|c}
\hline Termo & Fonte & $\begin{array}{c}\text { Ocorrências } \\
(1800-1900)\end{array}$ & Primeira Ocorrência \\
\hline \multirow{2}{*}{$\begin{array}{c}\text { General } \\
\text { glut }\end{array}$} & Jstor & 28 & $\begin{array}{c}\text { David Ricardo (1811) "The high price of bullion, a } \\
\text { proof of the depreciation of bank notes" }\end{array}$ \\
\cline { 2 - 4 } & Google & 89 & $\begin{array}{c}\text { Jean-Baptiste Say (1821) "Letters to Mr. Malthus: } \\
\text { On Several Subjects of Political Economy, and on the } \\
\text { Cause of the General Stagnation of Commerce". }\end{array}$ \\
\hline $\begin{array}{c}\text { Com- } \\
\text { mercial } \\
\text { crisis }\end{array}$ & Jstor & 295 & $\begin{array}{c}\text { John Wade (1826) "Digest of facts and principles on } \\
\text { banking and commerce: with a plan for preventing } \\
\text { future reactions" }\end{array}$ \\
\cline { 2 - 4 } & Google & 1.070 & $\begin{array}{c}\text { Pierre-Joseph Proudhon (1809) "The Poverty of } \\
\text { Philosophy" } \\
\text { Thomas Tooke (1826) "Considerations on the State } \\
\text { of the Currency". }\end{array}$ \\
\hline
\end{tabular}

Fonte: Jstor \& Google Scholar

O Gráfico 1 foi construído utilizando-se dados obtidos no Google Books Ngram Viewer ${ }^{12}$. O Gráfico 1a nos mostra que o termo general glut foi mais comum que commercial crisis apenas entre 1818 e 1834. Já as menções às commercial crisis começam a ganhar força a partir de 1836 e isso não parece ser por acaso. É durante os anos de 1836 a 1839 que ocorrem os chamados pânicos norte-americanos ou as crises anglo-americanas, nome dado a uma crise bancária de grandes proporções ocorrida nesses países, tendo depois contaminado França, Alemanha e Bélgica.

Observa-se ainda um grande pico no ano de 1861, isso se deve - provavelmente - ao fato de o ano de 1857 ter sido de severa crise especulativa, após um grande boom global de crédito graças às descobertas de ouro na Califórnia em 1849 e na Austrália em 1851. O pico seguinte no gráfico ocorre no ano de 1875, também poucos anos após o início de uma das mais graves crises financeiras de toda a história $^{13}$. O último pico ocorre no ano de 1896, sendo que1890 também foi um ano de crise bancária de escala global ${ }^{14}$.

12 Essa ferramenta é capaz de apresentar a ocorrência relativa de determinados termos em todos os livros digitalizados na base de dados Google. Isso corresponde a algo como 30 milhões de títulos, algo próximo a $6 \%$ de tudo o que já foi publicado.

13 Ver Benmelech \& Bordo (2007).

14 Ver Reinhart \& Rogoff (2010). 
Ou seja, os picos de referências ao termo commercial crisis ocorrem poucos anos à frente de grandes pânicos globais. Isso é razoável, dado que livros - obras de maior fôlego - demandam geralmente um intervalo mais longo entre o fato e a publicação.

No Gráfico 1b levantamos a ocorrência daqueles mesmos termos na base de dados do Jstor. Nota-se resultados obtidos a partir de ambas as bases de dados - que são bastante distintas, diga-se - são muito próximos, o que dá robustez à divisão temporal que utilizamos. Vemos que também nos journals a vida do debate em torno do general glut foi curta. Note-se ainda que os picos de referências as commercial crisis - 1839, 1848, 1858, 1869, 1886 e 1894 - acompanham mais de perto os pânicos ocorridos naquele período.

\section{Gráfico 1 [a e b]. Ocorrência dos termos "general glut" e "commercial crisis" de acordo com o Google Books e Jstor.}

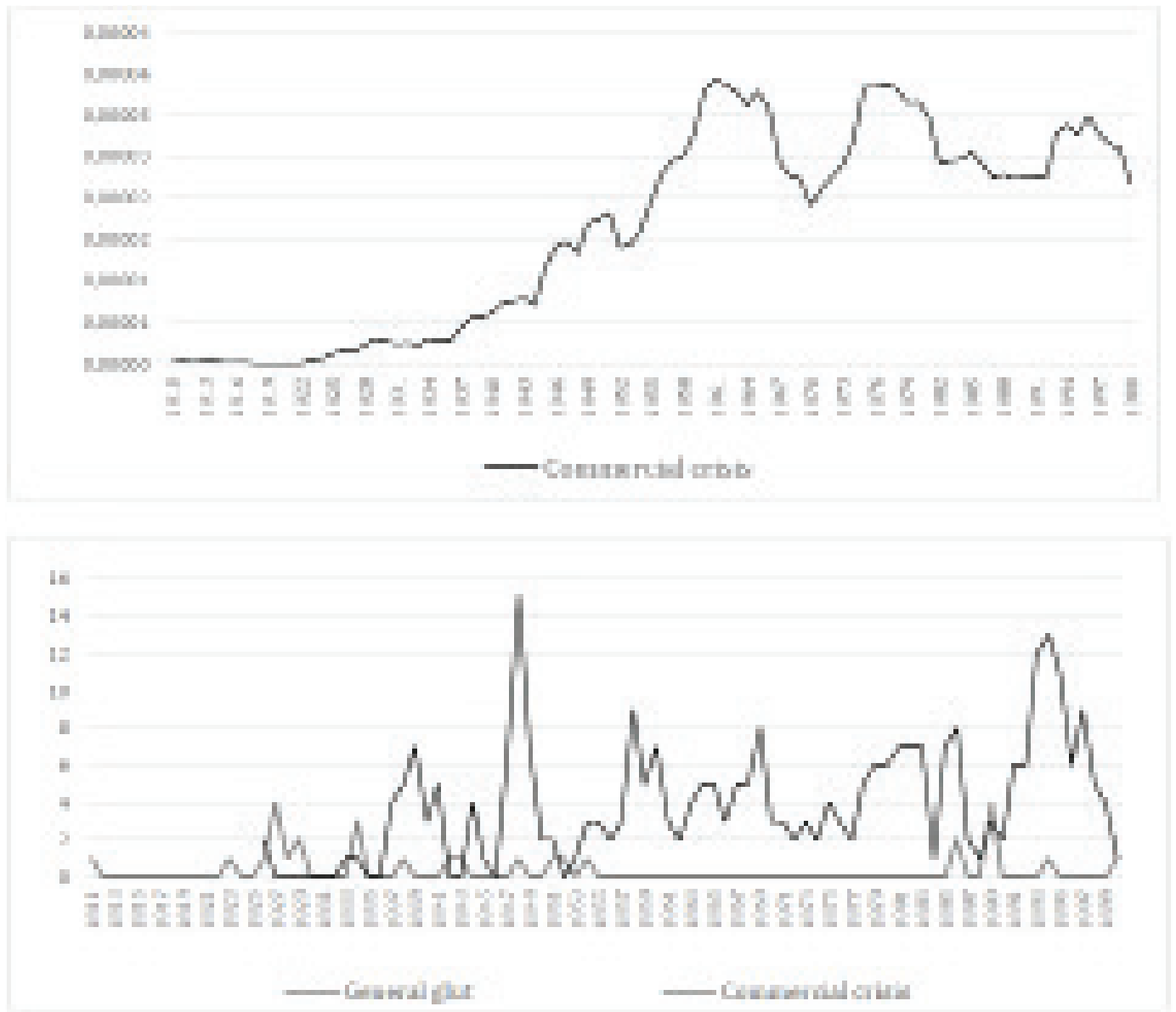

Fonte: Google Books Ngram Viewer e Jstor Data for Research. 
Crises econômicas de grande magnitude são eventos recorrentes na história do capitalismo, e seria bastante improvável que os economistas não voltassem sua atenção ao menos para essa face mais desagradável das flutuações. Será a partir da investigação desses "espetaculares cataclismos" - como define Persons (1925, p. 98) - que a teoria econômica irá começar a estruturar de forma mais sistemática uma análise sobre os ciclos em sua totalidade. Mas para que as investigações sobre commercial crisis dessem origem ao que conhece como business cycle - isso é, a sucessão periódica de movimentos de expansão e contração na atividade econômica - era preciso que os investigadores se livrassem de três empecilhos metodológicos; (i) as explicações exógenas (ou seja, que apelavam para fatores para além do escopo da teoria econômica), (ii) as teorias dos ciclos de periodicidade determinística (geralmente associadas às teorias exógenas) e (iii) as abordagens "particularistas" (de tal forma que cada crise se devia a fatores únicos e específicos, sendo irredutíveis a uma causa - ou conjunto de fatores - comum). Essa superação não seguiu um processo linear.

Autores como Schumpeter (1935; 1939), Spiethoff (1925) e Mitchell (1946[1927]) irão associar o nascimento do business cycle como campo independente de estudo ao lançamento do trabalho de Joseph Clèment Juglar (1819-1905) "Des Crises Commerciales et de leur Retour Périodique en France, en Angleterre et aux États-Unis” em 1862. A teoria das crises, apresentada por Juglar, é bastante objetiva baseando-se não apenas em especulações teóricas, mas derivada diretamente dos dados. Analisando o comportamento de um conjunto de variáveis monetárias (reservas metálicas, depósitos e circulação de notas bancárias) e reais (preço de cereais, receita pública, dados de comércio exterior), ficou evidente a relação entre o crédito e as flutuações econômicas. Acreditamos, porém, que tal como sugerido pelo título da obra, o texto de Juglar está inserido nas polêmicas das crises econômicas. Pode-se argumentar que sua obra representa um salto qualitativo nessa agenda de pesquisa - ainda isso algo controverso, como questiona Besomi (2011) - mas não o início da agenda de business cycles.

Da metade final do século XIX destacam-se ainda outros três autores: John Stuart Mill, John Mills e W. Stanley Jevons. As teorias de Mills e Mill são bastante próximas a de Juglar, assentadas sobre o papel do crédito em uma economia monetária (ou de trocas indiretas) e seus impactos secundários sobre o nível de especulação e a psicologia da comunidade, em cada uma das fases do ciclo (que na nomenclatura de John Mills (1867), são; o pânico, o período pós-pânico, a retomada ("revival") e o período especulativo). Segundo Stuart Mill (1885), o crédito e a psicologia explicam as crises da seguinte forma. Imagine que no instante $(t)$ cria-se entre os empresários de um setor $(n)$ qualquer, a expectativa de um aumento no preço da mercadoria e, consequentemente, da lucratividade do setor, no período $(t+1)$. Nesse caso, ainda no instante $(t)$, os empresários contraem empréstimos de forma a financiar um aumento nos seus estoques. Esse movimento, numa espécie de profecia autorrealizável, pode desencadear um aumento no preço observado da 
mercadoria. Se esse movimento de aumento de preços se mostrar consistente, especuladores começarão a ser atraídos para o setor $(n)$. Novas rodadas de aumento de preço e de lucratividade do setor podem se suceder, mas esse movimento não pode persistir por muito tempo. E pode ser que o movimento altista se descole de sua base real. O movimento de ajuste pode ser suave ou abrupto. Se os preços param de subir e todos desejam realizar seus lucros, livrando-se do ativo em questão, a queda nos preços será abrupta e exagerada. E se no momento de expansão o crédito é fácil e abundante, no momento da queda o crédito desaparece. Para Stuart Mill, o pânico é um caso extremo da crise.

\section{Gráfico 2 [a \& b]. Ocorrência dos termos “business cycles” e "trade cycles" (1910-1945)}

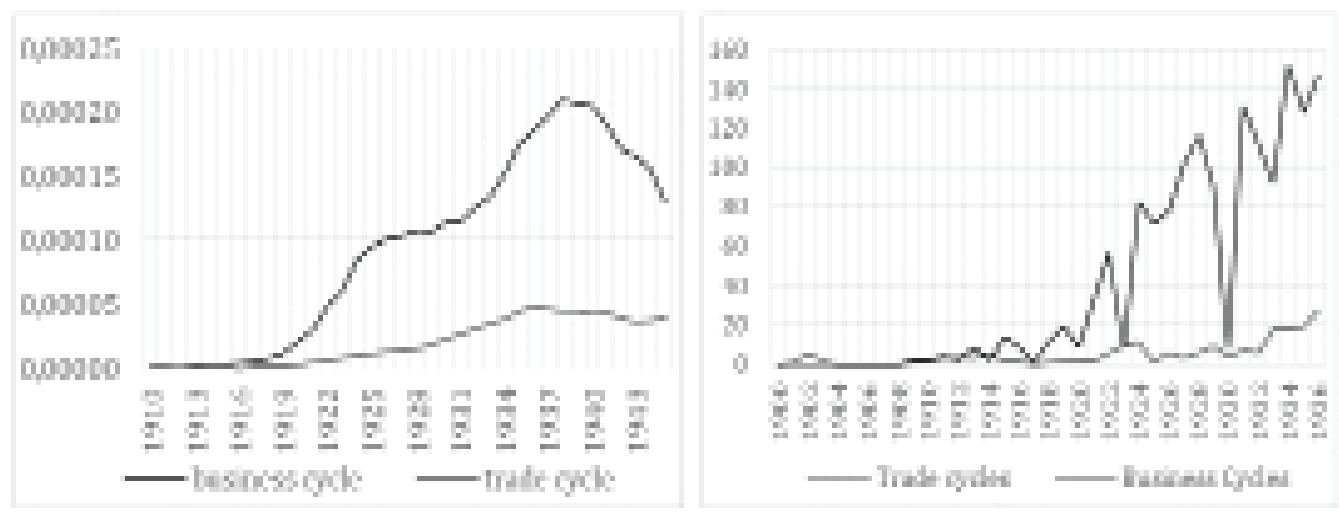

Fonte: Google Ngram Viewer \& Jstor.

Esses três autores - Juglar, Mill e Mills - já percebem as crises como endógenas, recorrentes e periodicidade não determinística. Ainda que os ciclos econômicos de dez anos tenham passado à história como "ciclos de Juglar", essa regularidade era simplesmente um fato da realidade do século XIX notado por Juglar como também por Marx, mas ambos afastam a ideia de que essa periodicidade é intrínseca ao processo econômico ${ }^{15}$.

O mesmo não ocorre, porém, em W. Stanley Jevons (1879). O fato de as crises se repetirem a cada dez anos (aproximadamente, entre 1701 e 1878) e dessas coincidirem com os ciclos solares (sunspots), calculados por Thorold Rogers (de 10.45 anos), pareceu-lhe evidência demasiadamente forte para ser tomada apenas como coincidência. Jevons irá determinar a causalidade do último para o primeiro. Mas incapaz

15 "Because output movements are not regular, modern macroeconomics has generally turned away from attempts to interpret fluctuations as combinations of deterministic cycles of different lengths. Efforts to discern regular Kitchin (3-years), Juglar (10-years), Kuznets (20-years), and Kondratiev (50-years) cycles have been largely abandoned as unproductive” (ROMER, 2006, p. 175-6). 
de verificar ciclos tão perfeitamente sincronizados na produção agrícola europeia, irá associar as crises no velho continente aos ciclos agrícolas registrados na Índia e outros países (sub e) tropicais. Assim, a variabilidade na produção daqueles países - causada pelos sunspots - será o impulso sobre as trocas comerciais europeias que iniciarão as crises generalizadas. Essa "coincidência" 16 fez com que se desse um passo atrás, obrigando, a partir daquele período, que o autor se justificasse sobre sua posição em relação à existência ou não de ciclos determinísticos sobre as variáveis econômicas.

Ainda que a teoria de Jevons não pareça ter atingido o mesmo grau de aceitação que a de Mill17, ela teve um número significativo de entusiastas. E ambas perduraram por décadas. Será apenas no século XX que as explicações exógenas e/ou determinísticas e/ou particularistas irão deixarão de ser (gradualmente) levadas em conta. Dois eventos marcam essa transição. O primeiro é a publicação da clássica obra de Wesley Mitchell em 1913. O outro é a Primeira Guerra Mundial (1914-1918).

O Gráfico 2 [a \& b] mostra de forma inequívoca que o uso do termo "business cycles" só começa por volta de 1913, ganhando então momento até por volta do final da década de 1930.

\subsection{O Debate sobre os Ciclos Econômicos (1913-1936)}

A Tabela 2 mostra que tanto o termo "business" como "trade cycles" têm suas primeiras aparições em 1909, e que enquanto o primeiro era o preferido entre os americanos, o segundo era o utilizado pelos ingleses.

Tabela 2: Dados de ocorrência no Jstor

\begin{tabular}{c|c|c}
\hline Termo & $\begin{array}{c}\text { Ocorrências } \\
(1900-1936)\end{array}$ & Primeira Ocorrência \\
\hline $\begin{array}{c}\text { Business } \\
\text { Cycle (s) }\end{array}$ & 4.602 & $\begin{array}{c}\text { Wesley C. Mitchell (1909) "The Decline in the Ratio of Banking } \\
\text { Capital to Liabilities" }\end{array}$ \\
\hline $\begin{array}{c}\text { Trade } \\
\text { Cycle }\end{array}$ & 1.605 & $\begin{array}{c}\text { H. W. Macrosty (1909) "Proposals for an Economic Survey of the } \\
\text { United Kingdom" } \\
\text { Sidney Webb (1909) "The Problem of Unemployment in the Uni- } \\
\text { ted Kingdom; With a Remedy by Organization and Training" }\end{array}$ \\
\hline
\end{tabular}

Fonte: Jstor Data for Research. A primeira referência que o Jstor aponta para o termo "business cycles" aparece em $1882 \mathrm{em}$ um texto do The British Medical Journal entitulado "Fatal Accidents in Various Occupations”. Decidimos ignorar essa observação. (") Observações entre 1936 e 1960.

16 Ver Mitchell (1946[1927]).

17 Em artigo do início do século XX, SELDEN (1902, p. 293) afirmava com sarcasmo: "The list of reasons which have been advanced at various times in explanation of panics is a long and amusing one. In several recent publications the 'sun-spots theory' is discussed with diverting seriousness, and a late issue of foreign magazine contains elaborate charts endeavoring to establish a relation between poor crops and crises". 
Wesley C. Mitchell (1874-1948), cujo texto de 1909 é o primeiro a usar o termo business cycle de acordo com os arquivos do Jstor, é ainda hoje amplamente reverenciado pelos economistas de todo o mundo, especialmente pelos americanos, tendo passado para a história graças aos seus trabalhos pioneiros sobre as flutuações econômicas ${ }^{18}$, nos quais se utilizava de uma abordagem quantitativa/estatística (ou, para os críticos, ateórica ${ }^{19}$ ) em busca de padrões nas séries econômicas. Seus trabalhos como Business Cycles de 1913, Business Cycles The Problems and Its Setting de 1927, Measuring Business Cycle de 1946 (em parceria com Arthur Burns) são todos marcos na disciplina. Seu trabalho de 1913, no entanto, se destaca historicamente. Isso não só por sua abordagem teórica sofisticada que tentava abarcar várias das teorias então existentes, mas, principalmente, pela apresentação exaustiva e rigorosa de dados econômicos para os Estados Unidos, Inglaterra e Alemanha para o período entre 1891 e 1910. Essa contribuição permitiu que o debate ganhasse um maior grau de cientificidade. Sua qualidade e importância foram reconhecidas de imediato, como atestam algumas das várias resenhas feitas à obra ${ }^{20}$. Em nossa interpretação é com Mitchell que essa agenda de pesquisa muda de patamar qualitativo, sendo ele um fundador mais apropriado do que Juglar.

Outro fator importante nesse salto qualitativo no debate sobre os ciclos foi o esforço, derivado do momento de guerra, dos países centrais na busca por estatísticas econômicas de boa qualidade. Esse movimento marca o início da Revolução da Contabilidade Nacional ${ }^{21}$. Esses eventos, de maneira gradual mas crescente -, permitiram a verificação de teorias e hipóteses de forma mais robusta e a consequente seleção de abordagens mais relevantes (ou mais operacionais) e/ou exclusão das menos robustas (ou menos operacionais), como também sentará as bases para o futuro desenvolvimento no campo da Econometria. Como afirma HAWTREY (1926, p. 169): "The output of literature on the subject of trade cycle has increased beyond precedent since the war". O Gráfico 2 parece corroborar Hawtrey. A mudança observada nos estudos dos ciclos foi não apenas quantitativa, mas também qualitativa. E esse fenômeno de sofisticação das teorias também irá transparecer na comparação entre as resenhas de Kershaw (1900) com a de Patterson (1915) e dessa com as de Persons (1926) e Mitchell (1946[1927]).

\footnotetext{
18 Ver Biddle (1996).

19 Ver Koopmans (1947)

20 Ver Persons (1914), Mudgett (1915), Sprague (1916), Clark (1917) (CLARK, 1917, p. 217).

${ }^{21}$ Ver Kendrick (1970).
} 


\section{As Resenhas}

Kershaw (1900) apresenta dois grupos de explicações para as flutuações; aquelas relacionadas às variações na produção agrícola (como a de W. S. Jevons) e aquelas baseadas no "mental mood of capitalists and bankers" (como a de Stuart Mill). Sendo que ele próprio desenvolve uma análise estatística baseada no primeiro tipo de explicação. $\mathrm{O}$ que sinaliza que ainda às portas do século $\mathrm{XX}$ as explicações agrícolas para flutuações econômicas do capitalismo ainda eram um ramo relevante das teorias.

Samuels (1976), a partir das anotações de um estudante, mostra que o curso de Commercial Crisis and Business Cycle na Universidade de Harvard, entre 1905 e 1906, ainda apresentava as teorias sobre as flutuações em dois grupos, "as que afirmavam que os ciclos eram gerados por uma tal rica variedade de causas que impossibilitavam a generalização, e que outra afirmava que os ciclos eram causados por 'causas permanentes'” (SAMUELS, 1976, p. 150).

A divisão de Harvard ecoa em E. M. Patterson (1915), o qual ainda distingue as teorias em dois blocos; exógenas e endógenas. No primeiro grupo estavam aquelas explicações que entendiam que o equilíbrio econômico era perturbado por eventos únicos, específicos e particulares, de forma que não haveria bases para um campo de estudo sobre as flutuações típicas (entre os autores destacados está Wilhelm G. F. Roscher, um dos fundadores e expoentes da Escola Histórica Alemã). $\mathrm{E}$ as tais causas unicas seriam, por exemplo, quebras de safra, descoberta de minas, invenções, abertura ou fechamento de rotas comerciais ou mercados consumidores, guerras e revoluções e a depreciação cambial. (Patterson, 1915, p. 136-7).

Já no segundo grupo, estavam aquelas teorias defendidas pela "maioria dos autores nos anos recentes", para os quais as "crises tendem a se repetir e que prosperidade, crises e depressão se sucedem de modo regular de tal modo que se autoriza o uso da palavra "ciclo"” (PATTERSON, 1915, p. 137). Havendo regularidade (ou um padrão) nos ciclos, era, pois, possível estipular uma "lei geral das flutuações". Essa última abordagem é subdividia em três categorias; (i) as teorias psicológicas, para as quais a explicação para os ciclos estava relacionada ao comportamento dos agentes econômicos (como em John Mills); (ii) as teorias "agrícolas" (determinísticas) - como em W. Jevons e (iii) as teorias "estruturais" ou "institucionais", que explicavam as flutuações a partir de características endógenas do funcionamento das economias modernas - cujo expoente era W. C. Mitchell, em seu trabalho 1913. Note-se que, ainda em Patterson (1915), não só as teorias exógenas formam um bloco importante, como nas endógenas ainda constam teorias do tipo determinísticas.

Warren M. Persons é uma figura fundamental nos estudos quantitativos dos ciclos econômicos no primeiro quarto do século XX, nos Estados Unidos. Tendo sido professor da Universidade de Harvard, presidente da American Statistical Association em 1923, primeiro editor do Review of Economic Statistics, em 1919 e diretor do Harvard Committee on Economic Research, sendo o responsável pelo desenvol- 
vimento do modelo de previsão econômica utilizado pela Harvard Economic Service [v. Friedman (2009)], além de ter dado contribuições seminais para estatística econômica. Persons (1926) divide as teorias dos ciclos em dois grandes grupos. Um que os se relaciona à própria dinâmica e instituições do sistema capitalista e outro que busca outras fontes explicativas.

Note-se que Persons (1926) ainda contempla as teorias de ciclos agrícolas exógenos, como também o encaixe no grupo de explicações institucionais. Jevons e seu filho Herbert S. Jevons (1875-1955) aparecem naquele grupo ao lado de Henrdy Ludwell Moore. Ainda no ano de 1921, Moore publica dois artigos na prestigiosa revista The Quaterly Journal of Economics. O primeiro, publicado em agosto, chama-se Generating Cycles Reflected in a Century of Prices. O segundo, de novembro, intitula-se The Origin of the Eight-Year Generating Cycle. Nesse último, por exemplo, o autor afirma a persistência por quase dois séculos de ciclos de oito anos nas colheitas dos Estados Unidos, Inglaterra e França, e que há uma coincidência desses ciclos meteorológicos com os ciclos econômicos. Sua hipótese: "these uniformities and agreements suggest that their cause must be sought in a cosmical cycle. The probable cause is the planet Venus eight-yearly periodic motion with respect to the Earth and the Sun" (MOORE, 1921, p. 1). A publicação desse artigo mostra que as teorias exógenas ainda não eram um total nonsense há menos de quinze anos do surgimento d'A Teorial Geral.

A divisão feita por Mitchell (1946[1927]), como o próprio autor admite, é bastante próxima à de Persons. Mas ainda que Persons e Mitchell sejam figuras de primeira grandeza, é certamente de Gottfried Harbeler (1900-1995) a resenha mais famosa sobre o assunto [v. Bioanovsky (2000) e Boianovsky \& Trautwein (2004)]. Prosperity and Depression: A Theoretical Analysis of Cyclical Movements, de 1937, foi uma obra escrita a pedido da Liga das Nações, com patrocínio da Rockefeller Foundation. O seu objetivo era não só catalogar todas as teorias sobre ciclos então existentes, mas também construir uma teoria qualitativamente superior à elas. Haberler foi professor na Universidade de Viena antes de trabalhar para a Liga, da qual se desligou para tornar-se professor da Universidade de Harvard em 1936. Haberler (1946[1937]) distingue quatro grupos de teorias: as de sobre-investimento, de subconsumo, as "agrícolas" e um grupo de estrutura miscelânea. Seria impossível analisar com profundidade as teorias de cada um dos autores citados nos esquemas de Persons (1926) e Haberler (1937). Por isso restringiremos nossos comentários a uma amostra de autores citados explicitamente por Keynes na TG.

Ludwig von Mises (1881-1973), um dos cardeais da escola austríaca, em seu livro de 1912 - The theory of money and credit - apresenta sua teoria dos ciclos econômicos como análoga àquela da escola de pensamento inglesa conhecida como British currency school e que, posteriormente, sofreria uma tentativa de resgate com o trabalho do influente economista sueco Johan Gustaf Knut Wicksell (1851-1926) "Interest and price", publicado em 1865. Seu argumento é que a capacidade de os bancos criarem crédito num volume acima dos seus ativos permite que as taxas de 
juros sejam reduzidas, tornando economicamente viáveis projetos que na ausência daquele mecanismo ficariam adormecidos. Essa seria uma causa central da fase ascendente do ciclo. Mas esse mecanismo é insustentável e quando o "peão para de girar", instala-se o pânico.

Friedrich Hayek (1899-1992) merece particular atenção, pois além de ser citado por Keynes, Lucas (1977) apresenta um excerto de uma obra sua como forma de corroborar sua interpretação histórica. A passagem começa com a seguinte afirmação: " $[\mathrm{T}]$ he incorporation of cyclical phenomena into the system of economic equilibrium theory [...] remains the crucial problem of Trade Cycle Theory". E mais: "By 'equilibrium theory' we here primarily understand the modern theory of the general interdependence of all economic quantities, which has been most perfectly expressed by the Lausanne School of theoretical economics". (HAYEK in LUCAS, 1977, p. 7). O trecho citado por Lucas (1977) é a junção de duas notas de rodapé do texto Monetary Theory and Trade Cycle de 1933. Necessário contextualizá-las. A primeira ${ }^{22}$ surge quando HAYEK (1933, p. 33) trata dos limites da estatística para a construção de sistemas teóricos (argumentação também utilizada por Schumpeter (1939: p. 24) e outros tantos autores). A ideia é que a verificação de correlações estatísticas não seria capaz de refutar ou suplantar as teorias derivadas a partir do sistema teórico dedutivo da economia, cujo exemplo mais bem acabado era o equilíbrio geral walrasiano. De tal forma que "[...] if $[\ldots]$ a theory is logically sound $[\ldots]$ then the best that statistical investigation can do is to show that there still remains an unexplained residue of process. [...] it could never prove that the determining relationships are different character from those maintained by the theory" (HAYEK, 1933, p. 33). Pode-se interpretar tal postura como uma crítica à abordagem quantitativa-estatística de autores como W.C. Mitchell. Já a segunda ${ }^{23}$ surge quando Hayek divide as teorias de flutuação em dois grupos: as monetárias e as não-monetárias ${ }^{24}$. Essas últimas eram ainda divididas em três subgrupos: as psicológicas; as que discutem a relação entre poupança e investimento e as que destacam as questões de técnicas produtivas. Para Hayek (1933), as teorias daquele último subtipo (as únicas consistentes/coerentes em sua opinião e que também se utili-

22 "Cf. The analysis concerning "Argument der Wirklichkeitswidfrigkeit" in the recent book by E. Carrel, [...], for a very acute methodological argument. He opposes the thesis of Löwe (which remains, however, despite his analysis, the basis of my own work) that the incorporation of cyclical phenomena into the system of economic equilibrium theory, with which they are in apparent contradiction, remains the crucial problem of trade cycle theory". (HAYEK, 1933, p. 13)

23 "By "equilibrium theory" we here primarily understand the modern theory of the general interdependence of all economic quantities, which has been most perfectly expressed by the Lausane School of theoretical economics. The significant basic concept of this theory was contained in James Mill's and J.B. Say's Théorie des Débouchés. [...]”. (HAYEK, 1933, p. 19)

${ }^{24} \mathrm{O}$ autor também apresenta uma distinção similar - ainda que não equivalente - entre teorias endógenas (cuja validade poderia ser verificada através da teoria econômica "pura”) e as exógenas (as quais são baseadas em hipóteses concretas - ou seja, empiristas - cuja validade deveria ser verificada caso a caso). 
zavam do modelo walrasiano como base) tinham que apelar para causas exógenas (invenções, por exemplo) para explicar as perturbações ao equilíbrio. Para Hayek, apenas a introdução da moeda seria compatível com as explicações endógena sobre as causas da divergência entre oferta e demanda no curto prazo. Essas variações seriam irrelevantes caso afetassem a todos os preços de maneira proporcional, mas não é isso o que acontece. Partindo da hipótese wickselliana de "taxa natural de juros”, Hayek (1933) postula que expansões (retrações) monetárias implicam em reduções (aumentos) na taxa de juros "de mercado", o que distorce o sistema de preços da economia, provocando uma produção excessiva (insuficiente) de bens de capital. Ainda que a citação de Hayek (1933) seja algo deslocada, em linhas gerais, não seria forçoso associar o seu aparato analítico com aquele de Lucas (1975): um modelo macro de equilíbrio geral de fundamentos walrasiano que explica as flutuações a partir de perturbações monetárias. Mas há pelo menos dois problemas. Em primeiro lugar, ainda que o walrasianismo ronde o pensamento de Hayek, objetivamente sua utilização é ainda bastante rústica e pouco operacional. Não se apresenta um modelo explícito de tal forma que não há qualquer "instrução para a construção de uma economia artificial”. Além disso, a visão metodológica de Hayek não permaneceu inalterada ao longo de sua produção intelectual. Em "Economics and Knowledge" de 1937, Hayek apresenta críticas severas ao método baseado no equilíbrio geral walrasiano.

O grupo de autores das teorias não-monetárias de sobre-investimento é bastante heterogêneo. $\mathrm{O}$ que os une é a hipótese de que os desajustes econômicos seriam provocados por fatores da esfera da produção como invenções, descobertas, abertura de novos mercados, e não por questões relacionadas à moeda e ao crédito. Entre os autores desse grupo destaca-se Joseph Schumpeter (1883-1950), provavelmente um dos maiores entusiastas do walrasianismo de todos os tempos. Seu livro "Business Cycles. A Theoretical, Historical and Statistical Analysis of the Capitalist Process" de 1939 - ainda que cronologicamente posterior à TG - parece-nos ser o melhor exemplo possível da tradição equilibrista sugerida por Lucas. Schumpeter (1939) afirma que o equilíbrio geral walrasiano não só é a norma teórica ("theoretical norm") a partir da qual se pode fazer análises rigorosas a respeito das flutuações econômicas, como também o expediente necessário para se determinar a própria Ciência Econômica como um campo independente de estudos. E mais, Schumpeter não só defende o método walrasiano como critica fortemente o marshalliano utilizado por Keynes no "Treatise on Money”. A caracterização feita por Schumpeter (1939) sobre sua "economia artificial" é significativamente mais exaustiva e rigorosa do que aquela de Hayek (1933), mas em ambos os casos se tem apenas uma descrição verbal (e virtualmente não operacional) do processo econômico.

No agrupamento "princípio do acelerador" estão aqueles autores para os quais variações na demanda/produção de bens de consumo têm um impacto significativamente amplificado sobre a demanda/produção de bens de capital. Destacamse os nomes de Arthur Spiethoff e J.M. Clark (filho do também economista John 
Bates Clark). Em Spiethoff (1901) os argumentos (também puramente verbais) se desenvolvem sob um esquema implícito do tipo "fluxo circular da renda", o qual apenas forçosamente pode ser associado a uma tradição "equilibrista" baseada na teoria da escolha. Em Clark (1917) argumenta-se que a indústria produtora de bens de capital atende a duas espécies de demanda; (i) a de manutenção e reposição do equipamento existente - que chamaremos arbitrariamente de tipo depreciação e (ii) a de ampliação da capacidade produtiva - tipo investimento. E cada uma dessas demandas obedece a uma regra distinta; a do tipo depreciação varia com o montante da demanda por bens finais, enquanto a depreciação depende da taxa de variação nas vendas (isso é, a "aceleração" das vendas). Assim, não seria necessário se observar uma redução no volume da demanda por bens finais para que se perturbe o equilíbrio do setor de bens de capital, mas sim que simplesmente caia sua taxa de crescimento. Não há qualquer descrição sobre o comportamento dos agentes econômicos ou da interação entre os mercados, nem mesmo uma discussão sobre as causas da "desaceleração" das vendas. O modelo implícito utilizado é patentemente de equilíbrio parcial, levam-se em conta apenas as interações entre as indústrias produtoras de bens de consumo e de bens de investimento.

As teorias de subconsumo são das mais antigas da Economia, recuando até os trabalhos de Malthus e Sismondi. O ponto fundamental que une todos os seus subtipos é a ideia de insuficiência das rendas monetárias e/ou dos gastos em bens de consumo em relação à produção agregada de bens. Esses subtipos se caracterizam por se sustentarem em uma ou outra hipótese fundamental na explicação do descompasso entre produção e gastos; (i) é o progresso técnico, as invenções e o excessivo acúmulo de capital que provocam a tendência de que a produção supere a capacidade de consumo da sociedade; (ii) há perda de poder de compra em algum ponto da economia - via entesouramenteo; (iii) o excesso de poupança (oversaving) na mãos dos empresários acaba por provocar uma deficiência da demanda efetiva e (iv) rigidez relativa de salários, o que significa que os salários não variam pari passu com o aumento da produção, de forma que o subconsumo é derivado dos mecanismos concentradores de renda resultantes do livre funcionamento da economia.

John A. Hobson (1858-1940), autor de Physiology of Industry (em coautoria com A. F. Mummery), publicado em 1889, é elogiosamente citado por Keynes em diversas passagens da TG. E há grandes semelhanças entre Keynes e a argumentação desenvolvida por aqueles autores ${ }^{25}$. Não só nas questões relativas à insuficiência de demanda efetiva e expectativas, mas também os autores teriam antecipado a análise do multiplicador de Kahn, ponto fundamental da teoria keynesiana ${ }^{26}$.

25 CLOWER \& HOWITT (1998, p. 6) afirmam: “Keynes’s Chapter 19 analysis bears a remarkable resemblance to that of Mummery and Hobson [...]" ou ainda "in any case, a post-Keynes reader of Mummery and Hobson cannot help but note so many similarities".

26 Ver Vercelli \& Sordi (2009) 
Em linha com a tradição sismondiana ${ }^{27}$, Hobson acredita na possibilidade de uma crise de superprodução na economia derivada do excesso de poupança. $O$ autor constrói sua argumentação a partir do diálogo crítico com as obras de Ricardo e, principalmente, de Stuart Mill. Interessante notar como o debate em torno do "general glut" continuava (e, em nossa análise, continua ${ }^{28} \mathrm{em}$ alguma medida) a ecoar nas discussões macroeconômicas. Para os autores, a capacidade de produção de uma sociedade, num determinado instante do tempo, tem um limite superior dado pela dotação de fatores e tecnologia disponíveis. Mas a produção realizada pode - e tende - a ser inferior a esse nível. Haveria, nas sociedades industriais, uma tendência ao excesso de poupança, ao passo que os mecanismos equilibrados dessa tendência seriam débeis ou inexistentes, de maneira que as crises de superprodução seriam uma constante.

A teoria puramente monetária de R.G. Hawtrey baseia-se em dois princípios fundamentais; (i) "that certain monetary or credit movements are necessary and sufficient conditions of the observed phenomena of the trade cycle" e (ii) "that the periodicity of these phenomena can be explained by purely monetary tendencies, which cause the movements to take place in succession and to be spread over a considerable period of years" (HAWTREY, 1926, p. 472). Difícil não associar essa abordagem àquela do Monetarismo. Talvez não por acaso, FRIEDMAN \& SCHWARTZ (1975, p. 32) nos apresentem outra leitura sobre a "macroeconomia clássica"; "Before the Great Depression, it was widely accepted that the business cycle was a monetary phenomenon".

Arthur Cecil Pigou (1877-1959), por exemplo, é encaixado tanto no grupo das teorias não monetárias de sobre-investimento, como no das teorias psicológicas. Seu livro "Industrial flutcuations", de 1927, apresenta um argumento psicológico sobre as crises muito próximo àquele que Keynes (1936) desenvolve no capítulo XII de sua obra. Em maio de 1936, pouco mais de três meses após a publicação da TG, Pigou publica na revista Economica uma resenha à obra. A resenha, como se esperaria de uma personagem que personifica o antípoda naquela obra, é essencialmente desfavorável a Keynes, exceto no que diz respeito às suas considerações psicológicas. As considerações de Keynes (1936) sobre a incerteza e o animal spirts não surgem do nada. Muito se fala do tratado probabilístico de Keynes e de sua defesa da filosofia frequentista como parte integrante do conceito de incerteza. Mas essas categorias psicológicas de Keynes são versões refinadas de ideias compartilhadas por uma série de economistas de sua época. Minnie T England (1913) é um exemplo inquestionável desses trabalhos pioneiros sobre os

${ }^{27}$ Haberler (1937, p. 118) também destaca os autores como representantes contemporâneos da tradição de teorias de subconsumo de Malthus e Sismondi. E ainda que seja um crítico dessa abordagem, Haberler (1937, p. 122) apresenta o texto dos autores como uma das mais bem elaboradas versões dessa abordagem.

28 Ver, por exemplo, os argumentos de Paul Krugman (2009) em seu texto "A Dark Age of macroeconomics". 
efeitos das ondas de otimismo e pessimismo sobre os investimentos e, consequentemente, do ciclo econômico.

As teorias de desajustamento (maladjustments), dizem respeito ao sobre-desenvolvimento de um determinado ramo da indústria, provocado ou por mudanças na demanda ou na oferta. Essa má alocação de recursos deve-se à complexidade da economia, à impossibilidade de coordenação das ações dos n empresários (de j ramos) e dos 1 consumidores (fazendo parte daquilo que Haberler (1946[1937]) denomina de "error theories of the business cycle"). Seus defensores (F.W. Taussig, Arthur Pigou, W. Mitchell e W. Beveridge) acreditam que os erros de projeção são pró-cíclicos; durante as expansões mais investimentos são realizados e quanto mais "distantes" (em termos temporais) a demanda estimada a ser atendida, maior a probabilidade de erro. Mitchell (1946[1927]) é um dos que destacam essa complexidade, seus "agentes representativos" são descritos a partir da ótica (velha) institucionalista e não da neoclássica. $\mathrm{O}$ autor é também enfático ao afastar a utilidade do conceito de equilíbrio estático para as análises de flutuações. O equilíbrio só seria útil se alguém o definisse "em termos de inúmeras forças em constante mudança, mudando a taxas distintas e influenciando uma as outras à medida que mudam", algo não disponível àquela época (Mitchell, 1947[1927], p. 186).

Essa narrativa deixa claro, pois a interpretação de Blanchard sobre o período pré-Keynes é extremamente mais satisfatória que aquela apresentada por Lucas. Havia uma grande diversidade de abordagens e que mesmo quando travestidas de equilíbrio geral, esse ainda se apresentava muito grosseiro, no máximo sob a forma do modelo de fluxo circular da renda. A tese da ancestralidade é certamente um expediente do tipo reinvenção da tradição (Arida, 1984). Lucas que se apresenta como o continuador de uma tradição injustamente esquecida e sua metodologia de microfundamentação da Macroeconomia como a conclusão de um trabalho iniciado pelos autores "clássicos". Keynes também se refere aos "clássicos", mas o que ambos se referem são aos ricardianos. Pensando em perspectiva, assim como Keynes é um sismodiano, Lucas é, certamente, um ricardiano: crê no funcionamento ótimo da economia de mercado, na tendência da economia trabalhar sempre ao nível máximo/ótimo de utilização dos fatores e defende ferozmente o método abstrato dedutivo baseado nas premissas walrasianas, entre outros.

\section{Sobre o Sucesso da Teoria Geral.}

A Teoria Geral do Emprego, do Juro e da Moeda, obra-prima de John Maynard Keynes (1883-1945), foi publicada em fevereiro de 1936, mas sua fama é anterior a essa data. Em 1936, Keynes já era uma figura conhecida e respeitada. Como acadêmico e polemista, Keynes tinha um currículo já robusto, tendo escrito, entre tantas outras, as seguintes obras: "The Economic consequences of the Peace” (1919), "A Treatise in probability" (1921), "A Tract on Monetary Reform" (1923), "The End of Laissez-Faire” (1926) "Treatise on Money" (1930), "Economic Possibilities for 
our Grandchildren" (1930) e "Essays in Persuasion" (1931). A editora Mac Millian soube se aproveitar da fama do autor e empreendeu um esforço de divulgação do trabalho em progresso sendo realizado por Keynes. A edição de dezembro de 1934, do Economic Journal, por exemplo, trazia uma propaganda da referida na qual se lia na chamada que a obra "The General Theory of Employment, interest, and money" do mesmo autor de "A treatise on Money" estava "in press". Propaganda semelhante aparece na edição de dezembro de 1935, na qual se avisa aos leitores que "In this book Mr. Keynes carries much further the ideas expounded in the first volume of his Treatise on Money". Na edição de março de 1936, portanto, no mês seguinte ao aparecimento do livro, a propaganda surge mais vigorosa, acompanhada da seguinte passagem do economista britânico George Douglas Howard Cole (1889-1959):

\begin{abstract}
“The most important theoretical economic writing since Marx's Capital, or, if only classical economics is to be considered as comparable, since Ricardo's Principles.... What he has done, triumphantly and conclusively, is to demonstrate the falsity, even from a capitalist standpoint, of the most cherished practical 'morals' of the orthodox economists and to construct an alternative theory of the working of capitalist enterprise.” G. D. H. COLE (New Statesman).
\end{abstract}

Tendo, porém, por referência as resenhas escritas imediatamente após sua publicação, a TG não parece ter sido recebida por todos com o mesmo entusiasmo de Cole, especialmente entre os economistas de maior renome. G. Haberler, A. Pigou, W. Leontieff, J. Viner, J. Schumpeter e F. Knight, já então autores consagrados e ainda hoje amplamente conhecidos, apresentam uma leitura bastante crítica de Keynes. Enquanto J. Hicks, A. Hansen, D. Champernowne e D. H. Robertson, autores comparativamente de menor prestígio à época, são os que apresentam análises mais elogiosas. Vale lembrar que John Hicks, um dos gigantes do pensamento econômico neoclássico do século passado, era então um promissor jovem economista - com 32 anos de idade e já tendo publicado em 1932 o influente "The theory of wages", mas ainda preparando sua grande obra "Value and capital" que só sairia em 1939. Hicks (1936) apresenta uma leitura bem mais entusiasmada do que aquela presente em seu famoso artigo de 1937.

Pigou (1936), como era de se esperar, apresenta uma leitura extremamente crítica do pensamento e também dos expedientes retóricos utilizados por Keynes. Para Leontieff (1936), a essência da obra de Keynes era o abandono da hipótese de que a função demanda é homogênea de grau zero. Knight (1937) ironiza Keynes por se utilizar do termo "teoria geral" e que as demais teorias seriam apenas casos especiais de seu sistema. Para ele, o valor real da obra era inversamente relacionado com suas pretensões ${ }^{29}$.

29 "Its value is, I think, to be sought in the opposite direction from that of its pretensions [...]" (KNIGHT, 1937, p. 100) 
Tabela 1: Algumas das principais resenhas à Teoria Geral, publicadas entre 1936 e 1937.

\begin{tabular}{|c|c|c|c|}
\hline \multicolumn{2}{|c|}{ Ranking* } & \multirow{2}{*}{ Autor } & \multirow{2}{*}{ Título } \\
\hline 1930 & 1940 & & \\
\hline- & {$[9]$} & G. Haberler & $\begin{array}{c}\text { Mr. Keynes" Theory of the "Multiplier": A Methodo- } \\
\text { logical Criticism (1936) }\end{array}$ \\
\hline$[5]$ & - & A. C. Pigou & $\begin{array}{c}\text { Mr. J. M. Keynes' General Theory of Employment, } \\
\text { Interest and Money (1936) }\end{array}$ \\
\hline- & {$[1]$} & J. Hicks & Keynes' Theory of Employment (1936) \\
\hline- & - & $\begin{array}{l}\text { D. Champer- } \\
\text { nowne }\end{array}$ & $\begin{array}{c}\text { Unemployment, Basic and Monetary: The Classical } \\
\text { Analysis and the Keynesian (1936) }\end{array}$ \\
\hline- & - & $\begin{array}{l}\text { D. H. Robert- } \\
\text { son }\end{array}$ & $\begin{array}{c}\text { Some Notes on Mr. Keynes' General Theory of Em- } \\
\text { ployment (1936) }\end{array}$ \\
\hline- & - & C. O. Hardy & $\begin{array}{c}\text { The General Theory of Employment, Interest, and } \\
\text { Money by Jobn Maynard Keynes (1936) }\end{array}$ \\
\hline- & - & A. Hansen & $\begin{array}{l}\text { Mr. Keynes on Underemployment Equilibrium } \\
\qquad(1936)\end{array}$ \\
\hline- & - & W. Leontieff & $\begin{array}{c}\text { The Fundamental Assumption of Mr. Keynes' Mone- } \\
\text { tary Theory of Unemployment (1936) }\end{array}$ \\
\hline$[12]$ & {$[19]$} & J. Viner & $\begin{array}{l}\text { Review: Mr. Keynes on the Causes of Unemployment } \\
\text { (1936) }\end{array}$ \\
\hline$[11]$ & - & J. Schumpeter & $\begin{array}{c}\text { The General Theory of Employment, Interest, and } \\
\text { Money by John Maynard Keynes (1936) }\end{array}$ \\
\hline- & {$[4]$} & F. Knight & $\begin{array}{c}\text { Unemployment: And Mr. Keynes's Revolution in } \\
\text { Economic Theory (1937) }\end{array}$ \\
\hline- & - & J. Meade & A Simplified Model of Mr. Keynes' System (1937) \\
\hline
\end{tabular}

Fonte: Jstor. (*) Quandt (1976)

Ocorre que as revoluções científicas não se dão pela conversão dos autores consagrados a um novo paradigma, mas sim pela ampla aceitação dos jovens. Schumpeter, em sua resenha, retrata $^{30}$ a excitação e ansiedade de seus alunos - es-

30 "Those who had the opportunity to witness the expectations of the best of our students, the impatience they displayed at the delay in getting hold of their copies, the eagerness with which they devoured them, and the interest manifested by all sectors of Anglo-American communities that are up to this kind of reading (and some that are not) must first of all congratulate the author on a signal personal success, a success not in the least smaller in the cases of negative reaction than in those in which the book elicited fervent admiration. The unfavorable reviews in a sense but testify to the reality of that success $[\ldots]$ ”. (SCHUMPETER, 1936, p. 791). 
tudantes de Harvard - demonstravam em relação à obra de Keynes. Uma parte da explicação do sucesso de Keynes está relacionada com o fracasso - percebido pela comunidade - da teoria econômica tradicional. É extremamente natural que nesses momentos em que a abordagem hegemônica parece ser um programa de pesquisa degenerado, os iniciantes voltem sua atenção para esquemas alternativos. É essa a rationale das revoluções científicas segundo Lakatos. E Keynes conseguiu apresentar uma estrutura de análise robusta e testável que era então o ponto alto da agenda sismondiana. É certo que a mudança no papel do economista como agente público, a contabilidade nacional, a econometria e o modelo IS-LM fazem parte desse processo. Mas a hipótese de Robert Lucas de que o modelo IS-LM de Hicks (1937) e Modigliani (1944) foi central para o sucesso de Keynes, apesar de intuitiva - dada a posição central que esse modelo desempenhou na Macroeconomia entre o pós-Guerra e o final dos anos 1960 - não parece ser tão robusta assim. O Gráfico 4 apresenta as citações aos três autores, de acordo com a base de dados do Google Scholar, para um período de 30 anos, entre 1936 e 1966. O que se observa é que à exceção de 1946, a linha de citações a Keynes (1936) permanece sistematicamente acima das demais, e a partir de 1947 essa distância apresenta uma clara tendência de aumento. Ainda que as informações do Gráfico 4 não sejam capazes de refutar a hipótese de Lucas, elas, porém, parecem enfraquecê-la. Ou ainda, em vez de "Sem IS-LM, nada de Keynes", o mais correto parece ser "Sem Keynes, nada de IS-LM".

Creditar o sucesso de Keynes aos desenvolvimentos na econometria tampouco é inquestionável. No Gráfico 5 apresentamos as citações à Teoria Geral e ao artigo de Klein \& Goldberger (1955) "Econometric model of the United States, 1929-1952” que não só é um marco da disciplina, como constante usado por Lucas, como exemplo, da macroeconometria keynesiana. Os dados se referem ao período 1955, ano de publicação do trabalho e 1976, ano da publicação do artigo da crítica econométrica de Lucas. O que vemos, novamente, é que as citações a Keynes são em número sempre muito superiores às citações ao Klein \& Goldberger. Esse resultado já sugere cautela ao se analisar a tese de Lucas.

A hipótese de Blanchard de superação positiva estrita tampouco parece razoável. A inexistência de experimentos cruciais na Economia e o problema da reconciliação problemática das matrizes teóricas (Arida, 1984) parecem afastar essa hipótese por princípio. É inegável que comparada à grande parte da literatura do período, a análise da TG é mais sofisticada - em termos de testabilidade e aplicabilidade - como também mais simples - no sentido de ser uma teoria mais enxuta, com menos inconsistências. Porém, não parece razoável dizer que Keynes foi o primeiro a estudar as inter-relações entre os três mercados da macroeconomia ou o que fez de maneira mais sofisticada em termos matemáticos. A teoria de Kalecki e outras apresentadas na resenha de Tinbergern (1935) sobre as teorias matemáticas dos ciclos econômicos mostram que nesse ponto existiam teorias pelo menos tão (ou mesmo mais) sofisticadas que a de Keynes. 
Gráfico 4 \& 5: Citações a Keynes (1936), Hicks (1937) \& Modigliani (1944) [De 1936 a 1966] \& Citações a Keynes (1936) e Klein \& Goldberger (1955) [De 1955 a 1976]

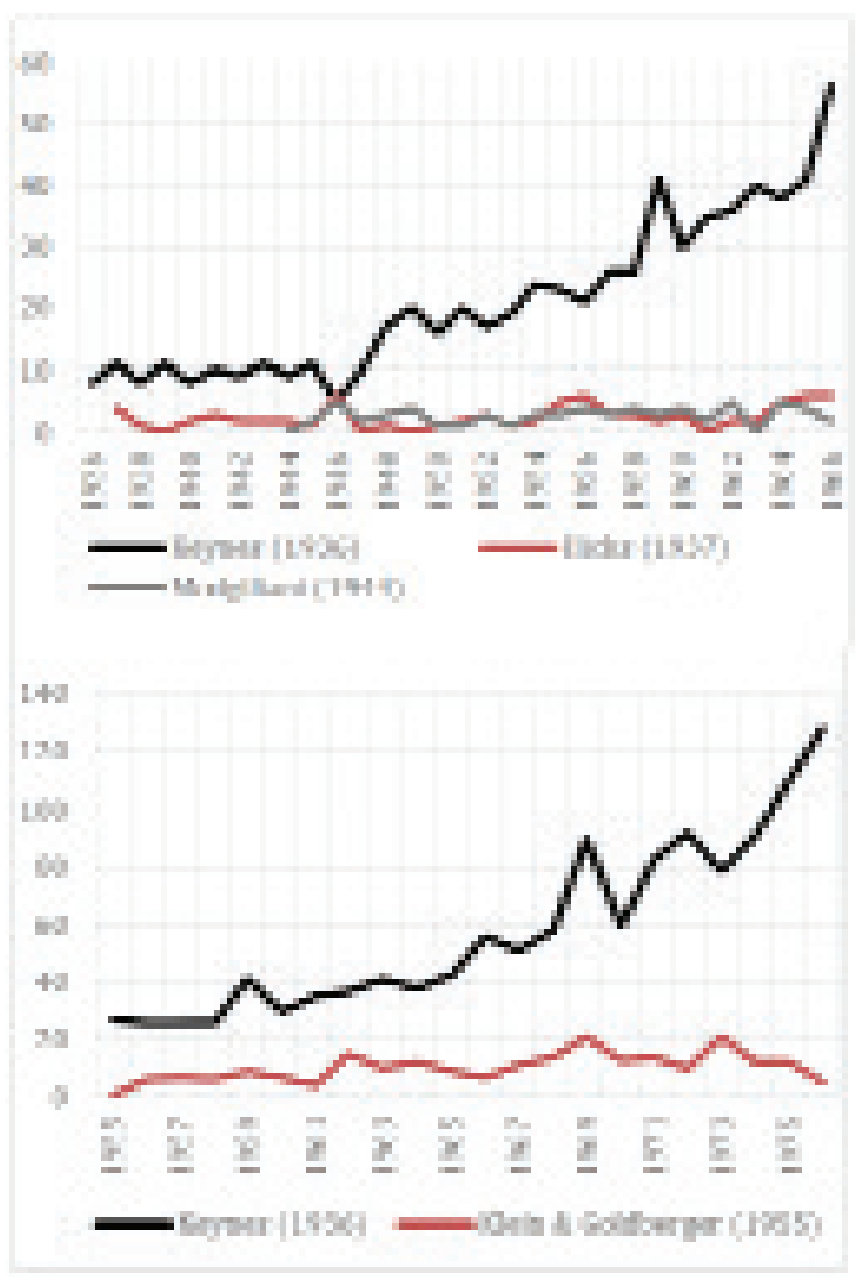

Fonte: Google Scholar

A dimensão sociológica da revolução keynesiana certamente não pode ser desprezada. $\mathrm{O}$ fato de ser um autor inglês, de uma das principais universidades do mundo, já famoso no mundo acadêmico e de grandes habilidades como polemista não são irrelevantes. A ambição do "economista como um dentista", capaz de fornecer diagnósticos simples para a solução do desemprego e para o bom funcionamento da economia, dava outra dimensão à profissão. O planejamento econômico que se tornou algo ordinário também nos países capitalistas - em parte graças à Keynes - demandava grandes contingentes de economistas. O prestígio dos economistas cresceu 
e por isso cresceu também sua participação na burocracia governamental, disputando espaço com engenheiros e advogados. Quando a crença no controle fino da economia foi ferida de morte nos anos 1970, o papel dos economistas apequenou-se. Se a teoria da evolução foi um dos grandes golpes sobre a vaidade humana, a teoria das expectativas racionais teve efeito análogo sobre os economistas. Afinal, entendemos tanto o verdadeiro modelo da economia como qualquer outro agente econômico.

Mas a roda da História nunca para. Enquanto nos anos 1970 foi o keynesianismo quem se apresentou como uma agenda de pesquisa degenerada. Assim como a crise de 1929 falseara nas previsões "clássicas" de que as crises eram setoriais e endogenamente reversíveis, a estagflação mostrara ser falsa uma das predições centrais do keynesianismo. Desde a crise do subprime de 2008, muita dúvida paira sobre a modelagem DSGE, nascida no início dos anos 1980. Alunos de Harvard ${ }^{31}$, por exemplo, se voltaram contra o curso de introdução a Economia de Greg Mankiw, demandando - entre outras coisas - o ensino de abordagens alternativas à neoclássica. O que significa que esses alunos não entendem a Economia como Física, mas sim a Economia como Sociologia. Pode ser que esse movimento esmoreça ou se traduza dentro de alguns anos em uma nova reviravolta na guerra de atrito entre as agendas ricardiana e sismondiana. Impossível antecipar, mas o cenário atual parece ser propício à mudança.

A verdade é que não é trivial explicar esse fenômeno de mudança de paradigma ou revoluções científicas. Trata-se de uma das questões fundamentais e mais complexas da Filosofia da Ciência. Mas nesse caso, ainda que a explicação de Lucas tenha um claro viés ideológico e busque sempre reduzir o papel de Keynes, a verdade parece estar mais próxima dele do que de Blanchard.

\section{Conclusão}

Nesse artigo discutimos a história da formação da Macroeconomia, desde o início do século XIX até o surgimento d'A Teoria Geral. Usando dados linguísticos e bibliométricos obtidos no Google Ngram Books e no Jstor, apresentamos a divisão da evolução da disciplina nas seguintes fases: (i) o debate sobre o general glut, de 1815 a 1836, (ii) as teorias sobre as crises de 1836 a 1913 e (iii) o período das análises de ciclos econômicos de 1913 a 1936. Mostramos ainda como nas últimas décadas do século XIX os autores se dividiam entre um grupo que acreditava que as crises eram causadas por variáveis monetárias e cuja periodicidade - apesar da regularidade - era estocástica, e outro grupo que creditava os ciclos a fatores para além da Economia e tratavam os ciclos como de periodicidade determinística. Refletindo a polêmica conhecida como "Methodenstreit", havia ainda uma divisão entre um grupo de autores que acreditava que cada crise era um fenômeno específico a ser explicado a partir de sua análise individual, enquanto outro acreditava haver um elemento comum a todas elas. Vimos que o grande marco do nascimento da teoria de ciclos econômicos foi o de Mitchell, em 1913, e como cresceu a produção nesta

31 http://harvardpolitics.com/harvard/an-open-letter-to-greg-mankiw/ 
área após a Primeira Guerra Mundial. Ao comparamos as leituras de Lucas e de Blanchard em relação ao período, notamos que a tese da ancestralidade de Lucas é simplesmente aquilo que Arida (1984) chamou de reinvenção da tradição, enquanto a leitura de Blanchard é bastante apropriada.

Argumentamos ainda que a história da Macroeconomia pode ser entendida como uma guerra de atrito entre duas agendas de pesquisa: a ricardiana e a sismondiana. E que Keynes é um autor da tradição sismondiana. Explicar as causas do sucesso não é algo trivial, mas através de dados bibliométricos mostramos que Keynes sempre foi mais influente que seus discípulos. De modo que a causalidade parece ser a inversa da sugerida por Lucas, ou seja, o modelo IS-LM e a macroeconometria são os que devem tributos a Keynes. Mas ainda que a hipótese de Lucas seja altamente enviesada em termos ideológicos, as dimensões que ele sugere modelos explícitos, contabilidade nacional, desenvolvimento da econometria, contexto histórico e questões sociológicas - parecem estar bem mais próximas da verdade do que a hipótese de superação positiva de Blanchard.

\section{Referências}

ARIDA, P. (1983). A história do pensamento econômico como teoria e retórica (No. 54).

Baumol, W. J. (1977). Say's (at least) eight laws, or what Say and James Mill may really have meant. Economica, 145-161. crossrefhttps://doi.org/10.2307/2553717

Benmelech, E., \& Bordo, M. (2007). The financial crisis of 1873 and 19th century American corporate governance," Working paper, Harvard University.

Besomi, D. (2011). 'Periodic Crises': Clement Juglar between Theories of Crises and Theories of Business Cycles Publisher: Research in the History of Economic Thought and Methodology volume 28-A: 169-283, 2010

Biddle, J. A Citation Analysis of the Sources and Extent of Wesley Mitchell's Reputation. History of Political Economy, 28:2, pp. 137-169. (1996). crossrefhttps:// doi.org/10.1215/00182702-28-2-137

Blanchard, O. (2000). What do we know about macroeconomics that Fisher and Wicksell did not?. The Quarterly Journal of Economics, 115 (4): 1375-1409. crossrefhttps://doi.org/10.3386/w7550

Boianovsky, M. (2000). In search of a canonical history of macroeconomics in the interwar period: Haberler's Prosperity and Depression revisited. Revista Brasileira de Economia, 54(3), 303-331.

Boianovsky, M., \& Trautwein, H. M. (2004). Haberler, the League of Nations, and the quest for consensus in business cycle theory in the 1930s. Inst. für Volkswirtschaftslehre. 
Clark, J. M. (1917) Business Acceleration and the Law of Demand: A Technical Factor in Economic Cycle. Journal of Political Economy, Vol. 25, No. 3 (Mar., 1917), pp. 217-235crossrefhttps://doi.org/10.1086/252958

Clower, R., \& Howitt, P. (1998). Keynes and the classics: an end of century view. Keynes and the Classics Reconsidered, 163-78.

Dimand, R. W. (1988). The origins of the Keynesian revolution. London: Elgar.

Dimand, R. W. (2003). Interwar monetary and business cycle theory: Macroeconomics before keynes. A Companion to the History of Economic Thought, 325. crossrefhttps://doi.org/10.1002/9780470999059.ch21

England, M. T. (1913). An Analysis of the Crisis Cycle. The Journal of Political Economy, 21(8), 712-734. crossrefhttps://doi.org/10.1086/252316

Friedman, M \& Schwartz, A. J. Money and Business Cycles apud NBER (ed.) The State of Monetary Economics, pp. 32-78. 1975

Friedman, W. A. (2009). The Harvard Economic Service and the problems of forecasting. History of Political Economy, 41(1), 57-88. crossrefhttps://doi. org/10.1215/00182702-2008-037

H. (ed.) Business Cycle Thoery. Selected Texts 1860-1939. Pickering \& Chatto, p. $55-88,(2002)$,

Haberler, G. (1937). Prosperity and depression (Vol. 24). Transaction Publishers.

Hawtrey, R.G. (1926) The Trade Cycle, The Economist, 75, P. 169-85

Hayek, F. (1937) Economics and Knowledge. Economica, New Series, Vol. 4, No. 13, p. 33-54. Feb., 1937)

Lucas, R. E. Jr. (1975). An equilibrium model of the business cycle. The Journal of Political Economy, 1113-1144.

Hayek, F. (1933) Monetary Theory and the Trade Cycle.

Hicks, J. R. (1936). Keynes' theory of employment. The Economic Journal, 238253. crossrefhttps://doi.org/10.2307/2225227

Hicks, J. R. (1937). Mr. Keynes and the" classics"; a suggested interpretation. Econometrica: Journal of the Econometric Society, 147-159. crossrefhttps://doi. org/10.2307/1907242 
Jevons, W.S. (1879) The Periodicity of Commercial Crises, and its Physical Explanation. Statistical and Social Inquiry Society of Ireland, Vol. VII, Part LIV, pp 334-342. Pp. 334-342, (August. 1879)

Kendrik, J. W. The Historical Developments of National-Income Accounts. Journal of History of Political Economy, Vol. 2, pp. 284-315, (1970). crossrefhttps:// doi.org/10.1215/00182702-2-2-284

Kershaw, J. B. (1900). An Investigation of the Cause of Trade Fluctuations.The Economic Journal, 474-486. crossrefhttps://doi.org/10.2307/2956834

Keynes, J. M. (1982 [1936]). A teoria geral do emprego, do juro e da moeda. São Paulo: Atlas.

Kindleberger, C. P., \& Aliber, R. Z. (2013) Manias, Pânicos e Crises - Uma História Das Crises Financeiras. Ed. Saraiva.

Klein, L. R., \& Goldberger, A. S. (1955). econometric model of the United States, 1929-1952.

Klein, L. R., (1968 [1950]). The Keynesian Revolution (Vol. 19). New York: Macmillan.

Knight, F. H. (1937). Unemployment: And Mr. Keynes's revolution in economic theory. The Canadian Journal of Economics and Political Science, 3(1), 100-123. crossrefhttps://doi.org/10.2307/136831

Koopmans, T. C. (1947) Measurement without Theory. The Review of Economics and Statistics, Vol. 29, No 3, pp. 161-172. (Aug. 1947) crossrefhttps://doi. org/10.2307/1928627

Krugman, P. (2009). A Dark Age of macroeconomics (wonkish). New York Times, 27.

Laidler, D. (1999). Fabricating the Keynesian revolution: studies of the inter-war literature on money, the cycle, and unemployment. Cambridge University Press.

Leontief, W. W. (1936). The Fundamental Assumption of Mr. Keynes' Monetary Theory of Unemployment. The Quarterly Journal of Economics, 192-197. crossref https://doi.org/10.2307/1882507, London.

Lucas Jr, R. E. (1977). Understanding business cycles. InCarnegie-Rochester conference series on public policy (Vol. 5, pp. 7-29). North-Holland. crossrefhttps://doi. org/10.1016/0167-2231(77)90002-1 
Lucas Jr, R. E. (1980b). Rules, discretion, and the role of the economic advisor. In Rational expectations and economic policy (pp. 199-210). University of Chicago Press.

Lucas, R. E. (1980a). Methods and problems in business cycle theory. Journal of Money, Credit and banking, 696-715. crossrefhttps://doi.org/10.2307/1992030

Lucas, R. E., \& Sargent, T. (1981). After keynesian macroeconomics. Rational expectations and econometric practice, 1, 295-319.

Mill, J. S. (1836). Da definição de economia política e do método de investigação próprio a ela. Bentham, Stuart Mill, 291-315.

Mill, J. S. (1985). "Princípios de economia política" in Os Economistas. Editora Abril Cultural, São Paulo - SP.

Mills, J. (1867) On Credit Cycles and the Origin of Commercial Panics. apud HAGEMANN,

Mitchell, W. C. (1927). Business cycles: the problem and its setting.

Modigliani, F. (1944). Liquidity preference and the theory of interest and money. Econometrica, Journal of the Econometric Society, 45-88. crossrefhttps://doi. org/10.2307/1905567

Moore, H. L. (1921). The origin of the eight-year generating cycle. The Quarterly Journal of Economics, 1-29. crossref https://doi.org/10.2307/1883777

Mudgett, B. D. (1915) Business Cycles by Wesley Clair Mitchell: Review. Annals of the American Academy of Political and Social Science, Vol. 60, America's Interests as Affected by the European War (Jul., 1915), pp. 259-260

PATTERSON, E. M. The Theories Advanced in Explanation of Economic Crises. Annals of the American Academy of Political and Social Science, Vol. 59, pp. 133147, (May 1915).

Persons, W. M. (1926). Theories of business fluctuations. The Quarterly Journal of Economics, 94-128. crossrefhttps://doi.org/10.2307/1885554

Pigou, A. C. (1936) Mr. J. M. Keynes' General Theory of Employment, Interest and Money. Economica, 3, 54-56. crossrefhttps://doi.org/10.2307/2549064 
Reinhart, C. M., \& Rogoff, K. S. (2010). From financial crash to debt crisis (No. w15795). National Bureau of Economic Research.cross refhttps://doi.org/10.3386/ w15795

Ricard, D. (1983) "Notas aos princípios de economia política de Malthus”, Ed. Abril Cultural, São Paulo - SP.

Romer, D. (2006). Advanced Macroeconomic Theory. Third Edition, Ed. Mcgrawhill.

Samuels, W. J. The Teaching of Business Cycle in 1905-1906: Insight into the Development of Macroeconomic Theory. Vol. 4, No 1, pp. 140-162. (1972).

Schumpeter, J. A. (1939). Business cycles (Vol. 1, pp. 161-74). New York: McGrawHill.

Schumpeter, J. The Analysis of Economic Change. The Review of Economics and Statistics, Vol. 17, No 4, p. 2-10. (May, 1935) crossrefhttps://doi. org/10.2307/1927845

Selden, G. C. (1902). Trade cycles and the effort to anticipate. The Quarterly Journal of Economics, 16(2), 293-310. crossref https://doi.org/10.2307/1882747

Sowell, T. (2006). On classical economics. Yale University Press.

Sprague, O. M. W. (1916) Business Cycles by Wesley Clair Mitchell: Review. Journal of Political Economy, Vol. 24, No. 6 (Jun., 1916), pp. 609-611crossrefhttps:// doi.org/10.1086/252843

TINBERGEN, J. Annual Survey: Suggestions on Quantitative Business Cycle Theory. Econometrica. Vol. 3, No., pp. 241-308 3 (Jul., 1935)

Vercelli, A., \& Sordi, S. Genesis and evolution of the multiplier-accelerator model in the years of high theory.

Recebido em 27.01.16

Aprovado em 03.06.16 